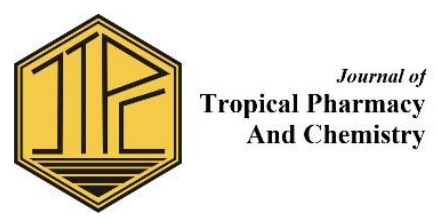

\title{
ISOLATION AND CHARACTERIZATION ENDOPHYTIC FUNGAL ISOLATE FROM PERONEMA CANESCENS JACK LEAF AND COPTOSAPELTA TOMENTOSA VAL. K. HEYNE ROOT
}

\author{
Arsyik Ibrahim*, M. Arifuddin, Wisnu Cahyo P, Wahyu Widayat, Mahfuzun Bone \\ Laboratory of Pharmaceutical Research and Development "FARMAKA TROPIS" \\ Fakultas Farmasi, Universitas Mulawarman, Samarinda, Indonesia \\ *email: achie.ibrahim@gmail.com
}

\begin{abstract}
Has been done Isolation, Characterization and Secondary Metabolite Endophytic Fungal Isolate from Peronema canescens Jack Leave and Coptosapelta tomentosa Valeton K. Heyne Root. The aim of this research is to know the number of fungal isolates, chromatogram profile and secondary metabolite group of endophytic fungal isolates from P. canencens leaves and C. tomentosa root. Characterization of endophytic fungal isolates was done macroscopically and microscopically. Identification of secondary metabolites endophytic fungal isolates were performed by chemical reaction test and TLC (Thin Layer Chromatography) method with specific spray reagents. The data of this study were obtained based on the number of endophytic fungal that can be isolated, observing macroscopic and microscopic morphological profiles, chromatogram profile and secondary metabolites of each endophytic fungal isolated. The results showed that endophytic fungal that can be isolated from P. canencens leaves four isolates, and two isolates from C. tomentosa root. Morphological profile macroscopic endophytic fungal of the six isolates showed a greenishcolored colony, white gray, clear black. Microscopic profile of each fungal isolate having spores, sprangiosphora, sporangium, conidia, hyphae and stolon. The identified secondary metabolites are: alkaloids, terpenoids, and flavonoids, and polyphenols.
\end{abstract}

Keywords: Peronema canesens Jack, Coptosapelta tomentosa, secondary metabolites, endophytic fungal

Submitted on: 16 May 2018

Accepted on: 03 June 2019

DOI: https://doi.org/10.25026/jtpc.v4i5.169

\section{INTRODUCTION}

Indonesia is a country that has biodiversity that can be processed into drugs various [1]. More than 1000 plant species can be utilized as raw material of medicine. Various types of bioactive compounds with functions various contained in plants, allegedly can be produced by endophytic microbes. Approximately 300,000 species of plants 
are scattered on the face of this earth, each plant contains one or more endophytic microbes consisting of fungal and bacteria. The ability of endophytic microbes to secondary metabolite compounds produce according to their host plants is a tremendous and reliable opportunity to secondary metabolites produce from endophytic microbes isolated from these host plants [2].

Endophytic fungal is it that lives in plant tissue at a certain period and is able to live by forming colonies in plant tissues without endangering its host [3]. Endophytic fungal are present in plant tissue systems, such as leaves, flowers, twigs or plant roots. The ability of endophytic microbes to produce secondary metabolite compounds according to their host plants is a tremendous and reliable opportunity to produce secondary metabolites from endophytic microbes isolated from these host plants [4].

Some of the traditional herbs used for treatment are Sungkai (Peronema canescens Jack) and Merung (Coptosapelta tomentosa Valeton K. Heyne) roots, young leaves of P. canescens by Dayak tribe use as cold medicines, fever, ringworms, used as for women a bath after delivery and as a gum toothache prevention [5]. As for the root of $\mathrm{C}$. tomentosa is also a native Indonesian medicinal plant widely used by people Kutai Kartanegara used for the treatment of diseases such as hypertension, pain (analgesic), diabetes mellitus, diuretic and anticancer [6].

The chemical compounds contained in the leaves of $\mathrm{P}$. canescens include $\beta$ sitosterol, phytol, $\beta$ - amyrin and several diterpenoids, among others: peronemin compounds A1, A3, B2, B2, B3, C1 and peronemin D1 [7], essential oils, lantaden terpenoid A compounds, lantaden B, lanthanolic acid, lantat acid, and class of lantonin alkaloids [8]. In addition, the crude extracts of methanol and ethyl acetate fractions contain classes of alkaloids, terpenoids, steroids, flavanoids, phenolics and saponins [9]; [10]. Several studies of the bioactivity of P. canescens leaf have been reported, among others, nhexane extract, ethyl acetate bark of P. canescens antioxidant effect [11]. Activities crude extract methanol as antibacterial [9]. Methanol extract and nhexane fraction of $\mathrm{P}$. canescens leaves are active against the shrimp larvae [12].

The secondary metabolite of $\mathrm{C}$. tomentosa root contains secondary metabolite classes such as alkaloids, flavonoids, tannins, phenolics, and sapaonins, and its bioactivity to Artemia salaina Leach obtained $\mathrm{LC}_{50}$ values of $346,74 \mu \mathrm{g} / \mathrm{mL}$ for ethyl acetate extract, and 933.25 $\mu \mathrm{g} / \mathrm{mL}$ for the extract n-butanol [13]. In addition, the antioxidant activity value obtained by $\mathrm{LC}_{50}$ methanol crude extract was $113,60 \mu \mathrm{g} / \mathrm{mL}$, n-hexane fraction $69,02 \mu \mathrm{g} / \mathrm{mL}$, ethyl acetate fraction $97,64 \mu \mathrm{g} / \mathrm{mL}$, and n-butanol fraction $432,30 \mu \mathrm{g} / \mathrm{mL}$ [6].

Although it is well known that the leaves of P. canescens and C. tomentosa roots contain many secondary metabolite groups and chemical compounds and have many uses, to support and supplement previously reported research results, it is necessary to explore potential $\mathrm{P}$. canescens leaf and $\mathrm{C}$. tomentosa root through various research methods, one research method that can be done is the search for natural chemical compounds can be done through a biological approach that is the method of endophytic fungal isolation in vitro. The aim of this research is to know the number of endophytic fungus isolated from $\mathrm{P}$. canencens leaf and $\mathrm{C}$. tomentosa valeton root is to know the morphological profile, chromatogram profile and secondary metabolite group of endophytic fungal isolates from $\mathrm{P}$. canencens leaf and $\mathrm{C}$. tomentosa roots. 


\section{MATERIALS AND METHODS}

\section{Plant materials.}

Part of the plant used is the leaves of P. canencens Jack, obtained from Tanah Merah-Samarinda, and C. tomentosa Valeton K. Heyne root obtained from Kutai Kartanegara, both samples has been determined by Dendrology Laboratory Faculty of Forestry, Mulawarman University.

\section{Media and reagent.}

The materials used in the study were Aquadestilata, medium PDA (Potato Dextrose Agar), MEA (Malt Extract Agar), PDB (Potato Dextrose Broth) and NA (Nutrient Agar), $0.9 \% \mathrm{NaCl}$ solution physiological. Reagent Dragendorf, Liebermann-Bouchard, $\quad 10 \% \quad \mathrm{H}_{2} \mathrm{SO}_{4}$, $\mathrm{FeCl}_{3}$, Sitroborat, Thin Layer Chromatography plate.

\section{Research procedure}

\section{Isolation of endophytic fungal.}

Leaf and root surfaces were cleaned with running water, sterilized for 1 minutes leaf surfaces with $70 \%$ alcohol, then immersed for 3 minutes with $5.25 \% \mathrm{NaOCl}$ (sodium hypochlorite), soaked for 30 seconds with $70 \%$ alcohol. Dried preparate with sterile tissue, leaves and roots are cut horizontally or longitudinally with size \pm 1 $\times 1 \mathrm{~cm}$ using a sterile knife. The preparate of leaves and roots were attached to a 100 $\mu \mathrm{g} / \mathrm{mL} \quad$ PDA medium contains chloramphenicol (PDAC) in a Petri dish, incubated for 7-14 days at room temperature $\left(25^{\circ} \mathrm{C}\right)$. Observations are done every day until a visible colony of fungal grows.

\section{Endophytic fungal colonies purification.}

Fungal colonies grown on PDAC medium, purified by inoculation into a new PDA medium, were incubated for 5 to 7 days at room temperature $\left(25^{\circ} \mathrm{C}\right)$ until a pure endophytic fungal isolate was obtained by viewing the characteristics visually [14].

\section{Endophytic fungal isolates characterization.}

Characterization of endophytic fungal isolates was done both macroscopic and microscopic. Macroscopic observation was done by looked at the shape and color of the endophytic fungal colonies on the Petri dish. While the microscopic characterization done direct and indirect observation a camera microscope using. Direct microscopic observations of fungal isolates were inoculated on glass objects which then spilled with methylen blue reagent and observed under a microscope. Indirect observation, on the glass object is added 1 - 2 drops of medium PDA above glass object closed with cover glass, incubated at room temperature $\left(25^{\circ} \mathrm{C}\right)$ for 7 days and observed by microscope.

\section{Secondary metabolite production of endophytic fungal isolates.}

Seed endophytic fungal isolates were taken $20 \mathrm{~mL}$, and added to $250 \mathrm{~mL}$ of PDB media in Erlenmeyer and then incubated for 5-7 days with shaking. Then filtered using Whatmann paper number 41 . Miselia collected, dried in oven, then extracted using methanol for one day, evaporated in oven $40^{\circ} \mathrm{C}$ temperature. The extract was used for the identification of secondary metabolites with direct chemical reagents and TLC method.

\section{RESULT AND DISCUSSION}

One effort to find and propagate raw materials of drugs can be done biologically microbiology through the process of isolation of endophytic fungal. Propagating and reseach raw materials of drugs through biological means can be done on natural materials (plants/animals) with various criteria such as: plants have been nearing extinction, very long growth of 
development, very little active secondary metabolites produced, verry difficult of cultivation, the location of active metabolite on the part that if excessive exploitation can accelerate the extinction so as to affect the environment of ecosystem.

Peronema canencens and C. tomentosa are plants that have the above criteria is having a potentially active metabolite but the growth is long enough and if exploited can accelerate extinction. The scientifically these plants, especially the leaves and roots contain secondary metabolites of alkaloid compounds, caratenoid, phenolic compounds, flavonoids, saponins, tannins and steroids, both have high toxicity potential than the potential for development as raw materials and drugs potential compounds.

\section{Endofphytic Fungal Isolation}

Isolation is a way to separate a microbe from its environment, so that a culture is obtained which is not mixed with other or called pure cultures [15]. Isolation of endophytic fungal was done by using sterilization method of surface stratified. The surface sterilization method was used as a pretreatment to isolate endophytic fungal originating from fresh plant organs [16]. Endophytic fungal can be isolated from plant tissue systems, such as: leaves, flowers, twigs, or plant roots.

$\mathrm{P}$. canencens leaves and C. tomentosa roots that have been sterilized surface, opened the tissue by way of horizontally sliced. The sliced tissue is then attached of the medium of PDA to the surface which has been added chloramphenicol antibiotics. The addition of chloramphenicol serves to suppress the growth of contaminant bacteria and endophytic. These antibiotics work by blocking the enzyme peptidyl transferase on the 50s ribosome. As a result of such enzyme blocking the protein synthesis stop process [17]. According to Jawetz [18], chloramphenicol antibiotic is a broadspectrum bacteriostatic that is active against positive or negative gram bacteria aerobic and anaerobic.

Based on the result of isolation of endophytic fungal which has been purification, obtained 4 isolate from $\mathrm{P}$. canencens leaf which each isolate is given DS21, isolate DS22, isolate DS23 and isolate DS74 code, while isolate of fungal from $\mathrm{C}$. tomentosa root obtained 2 isolate and given AM61 and AM102 code.

\section{Profile of purified fungal isolates from $P$. canencens leaf}

The purified endophytic fungal isolates were then characterized. This characterization aims to determine the morphology of endophytic fungal isolates through microscopic and microscopic observations. The profiles of each isolate are described as follows:

\section{Morfology fungal isolates of macroscopic}

The results of observation of DS21 isolates on macroscopic, showing colonies of greenish black, rounded shapes clustered, irregularly wavy colony edges, smooth fungal surfaces. The DS22 isolate shows a round, grayish white, shaped fibers with thin threads separated, the edges of irregular colonies, smooth and irregular colony surfaces. The DS23 isolate shows white colored colonies, fibrous shape, smooth, wavy colony edges, smooth colony surface, forming air bubbles on yellowish surface medium rather whitish. The DS74 isolate show white colony surface, black colony base, mushroom shape like cotton, filamentous, irregularly shaped root-shaped colony, have black pigment. Profile of macroscopic morphology fungal isolates of DS21, DS22, DS23 and DS74 can be seen in Figure 1. 


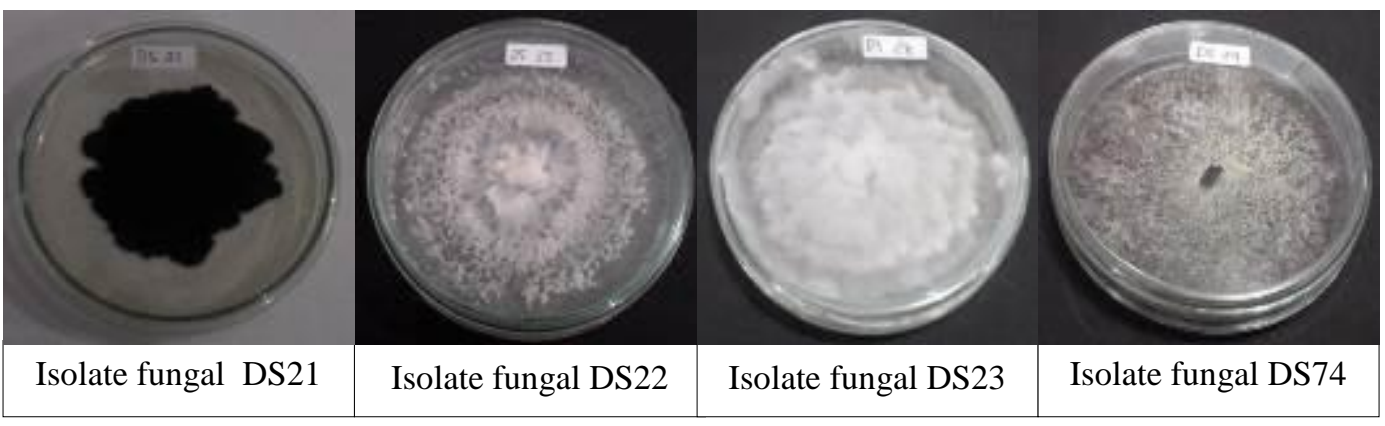

Figure 1. Profile of macroscopic morphology isolates fungal of DS21, DS22, DS23 and DS74.
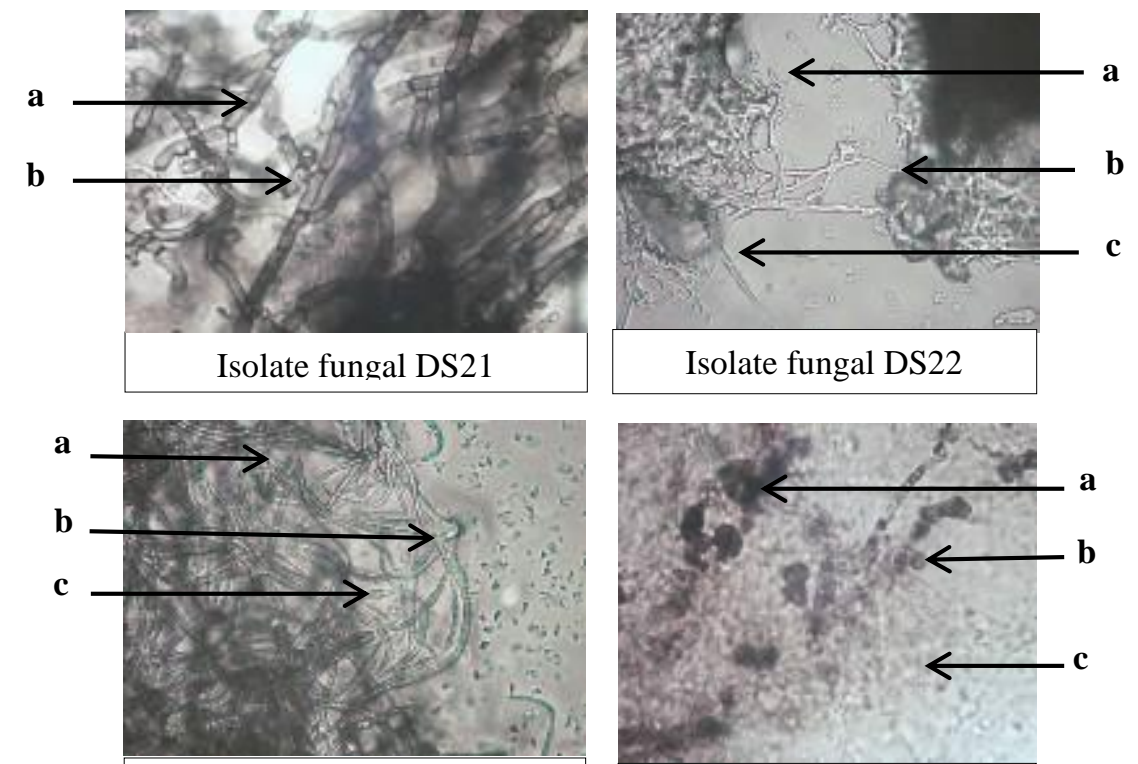

Isolate fungal DS23

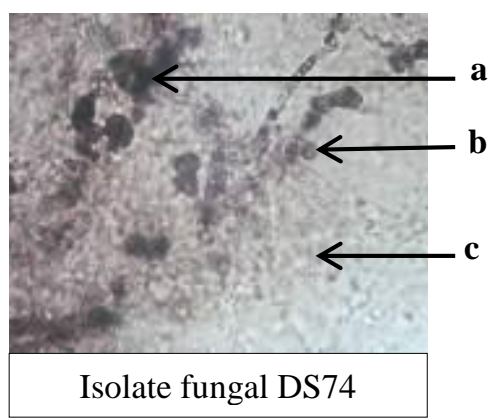

Figure 2. Profile of microscopic fungal isolates DS21, DS22, DS23 and DS74 400x magnification.

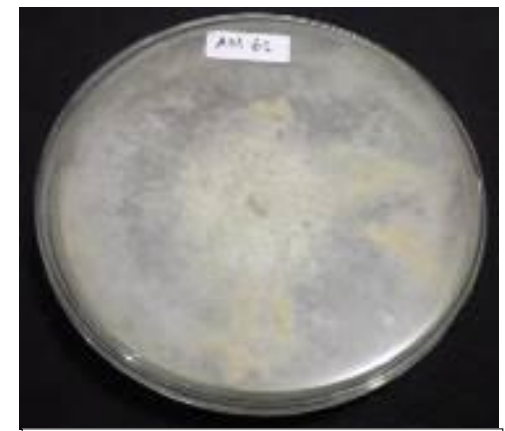

Isolate fungal AM61

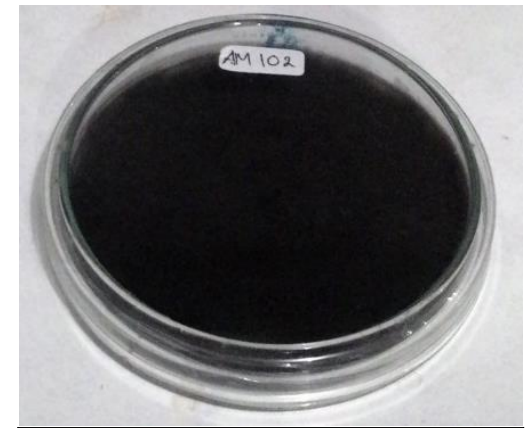

Isolate fungal AM102

Figure 3. Profile of macroscopic morphology of isolates AM61 and AM102 


\section{Morphology isolates fungal of microscopic}

The result of observation microscopic isolate of DS21 at 400x enlargement indicates the fungus has (a) sprangiosphora, and (b) sporangium. As for the isolate fungal DS22 there are (a) spores, (b) sprangiosphora and (c) stolon. Microscopic fungal DS23 isolates showing the fungus having (a) sprangiosphora, (b) spores, and (c) hyphae. Isolate of DS74 fungal having (a) sprangiosphora, (b) spores, and (c) conidia. Profile of microscopic fungal isolates DS21, DS22, DS23 and DS74 can be seen in Figure 2.

\section{Profile of purified fungal isolates from C. tomentosa root}

The purified endophytic fungal isolates were then characterized by endophytic fungal isolates, to determine the morphology of endophytic fungal isolates through macroscopic and microscopic observations. The profiles of each isolate are described as follows:

\section{Morphology fungal isolates of macroscopic}

The observations of AM61 isolate are macroscopic, showing colonies of white, and yellow cloudy, smooth surfaces resembling cotton. There air bubbles on the surface of the medium, the edge of irregular colonies, have a pink yellow pigment. For macroscopically isolated fungal AM102, the colonies are clear black, circularly irregularly shaped with varying sizes, there are mycelium-like roots in medium and blackish-gray attached, the edges of flat colonies, containing black pigments. Macroscopic images isolate of AM61 and AM102 can be seen in Figure 3.

\section{Morphology fungal isolates of microscopic}

The observation results of AM61 isolates microscopic, at 400x magnification showed the fungus had (a) sprangiosphora, (b) spores, and (c) conidia. As for AM102 fungus isolates there are (a) sprangiosphora, (b) spores, and (c) Stolon. Microscopic observation of AM61 and AM102 isolates can be seen in Figure 4.

\section{Secondary Metabolite Production}

Each plants usually contains several endophytic fungal of producing a secondary metabolite compound similar to that of its host, thought to be the result of genetic recombination or co-evolution from host plant in endophytic fungal. One way the its to adapted is by adopting some genetic information (DNA) from host plant. That matter a characteristic chemical of its to produce component in host plant [19].
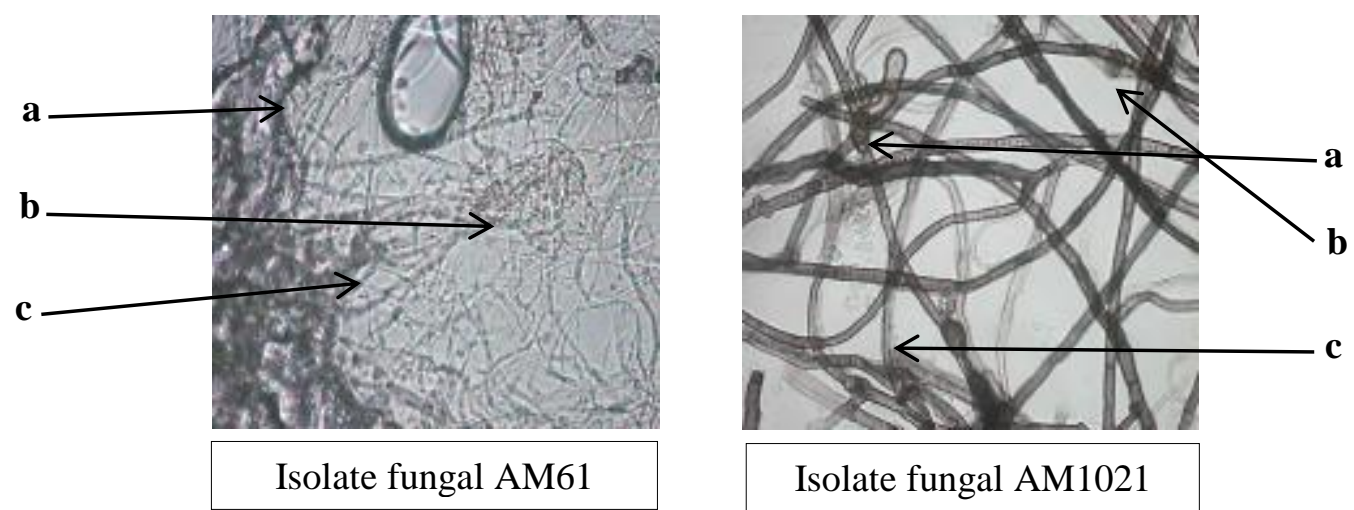

Figure 4. Profile of microscopic morphological of isolates AM61 and AM102 magnification $400 x$ 
According to Carlile [20] the secondary metabolism of the endophytic fungal generally occurs at a time when the growth phase to an end and begins to enter its stationary phase. It supports the statement [15], which states that the secondary metabolites of endophytic fungal can be harvested in the stationary phase growth its. The stationary phase can occur when, there is a balance between the number of cells divided by the numbered of cells that are dead.

The endophytic fungal isolates obtained were seeded using a liquid growth medium of PDB (Potato Dextrose Agar), which was then incubated using a rotary shaker. The incubation process is performed with agitation to satisfy the necessary oxygen requirements in the growth of the endophytic fungal and maintain the nutrient homogeneity present in the medium used. The result of the process is a mycelium of fungal isolates which is then dried and extracted by maceration method using methanol solvent. Methanol solvent is a universal solvent which can dissolve polar and nonpolar active compounds. The viscous extract obtained is then dried and used for secondary metabolite identification.

\section{Profile spot isolate fungal of UV254 nm, UV366 $\mathrm{nm}$ and H2SO4 10\%}

Identification of secondary metabolite groups from methanol extracts of fungal isolates using chemical reaction test method (tube test) and TLC. The principle of the TLC method is based on the separation of chemical components by adsorption and partition, in which the chemical component moves up following the mobile phase due to adsorbent absorption of the chemical components at different rates according to their polarity, causing the separation of active compounds in spot spots on the chromatogram plate [21].

Isolation of fungal spotted to isolates used eluent was hexane: ethyl acetate (3:1) was further spotting observed using spotting of $10 \% \mathrm{H}_{2} \mathrm{SO}_{4}$, UV254 $\mathrm{nm}$ and UV366 $\mathrm{nm}$ rays, obtained Rf (rate of flow) values of each fungal isolate. The Rf value of each spot of elution spot can be seen in Table 1.

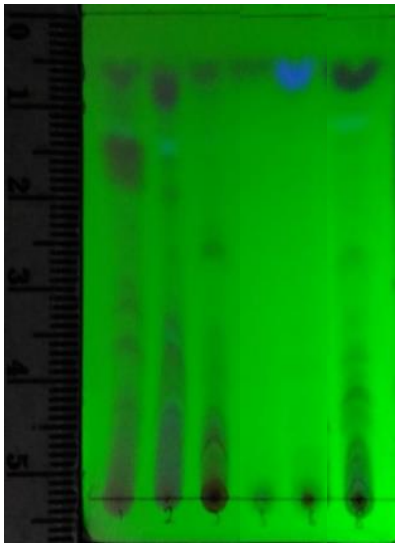

UV254 nm

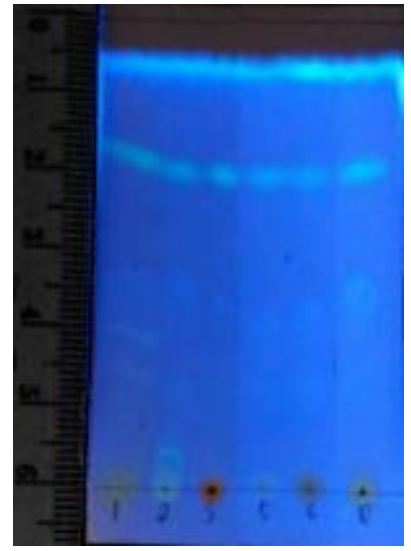

UV366 nm

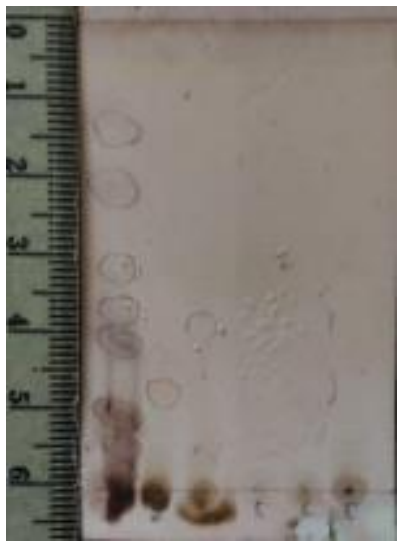

$\mathrm{H}_{2} \mathrm{SO}_{4} 10 \%$

Figure 5. Chromatogram of methanol extract endophytes fungal isolate from P. canescen leaf and C. tomentosa root 
Table 1. Rf value spot extract methanol endophytes fungal isolate from P. canescen leaf and C. tomentosa root.

\begin{tabular}{|c|c|c|c|c|}
\hline \multirow{3}{*}{ No. } & \multirow{3}{*}{ Sample (Code) } & \multicolumn{3}{|c|}{ Spotting } \\
\hline & & UV $254 \mathrm{~nm}$ & UV $366 \mathrm{~nm}$ & $\mathrm{H}_{2} \mathrm{SO}_{4} 10 \%$ \\
\hline & & Rf value & Rf value & Rf value \\
\hline \multirow{8}{*}{1} & \multirow{8}{*}{ DS21 } & 0.25 & 0.25 & 0.03 \\
\hline & & 0.33 & 0.33 & 0.08 \\
\hline & & 0.42 & 0.42 & 0.62 \\
\hline & & 0.77 & 0.72 & 0.32 \\
\hline & & & & 0.38 \\
\hline & & & & 0.45 \\
\hline & & & & 0.63 \\
\hline & & & & 0.78 \\
\hline \multirow{5}{*}{2} & \multirow{5}{*}{ DS22 } & 0.05 & 0.08 & \multirow{5}{*}{0.20} \\
\hline & & 0.08 & 0.12 & \\
\hline & & 0.12 & 0.22 & \\
\hline & & & 0.42 & \\
\hline & & & 0.67 & \\
\hline \multirow{3}{*}{3} & \multirow{3}{*}{ DS23 } & 0.12 & 0.22 & \multirow{3}{*}{0.33} \\
\hline & & 0.15 & 0.40 & \\
\hline & & 0.18 & 0.65 & \\
\hline \multirow{3}{*}{5} & \multirow{3}{*}{ DS74 } & & 0.17 & \multirow{3}{*}{ - } \\
\hline & & - & 0.33 & \\
\hline & & & 0.63 & \\
\hline \multirow{3}{*}{6.} & \multirow{3}{*}{ AM61 } & & 0.03 & \multirow{3}{*}{-} \\
\hline & & - & 0.37 & \\
\hline & & & 0.63 & \\
\hline \multirow{2}{*}{8.} & \multirow{2}{*}{ AM102 } & 0.05 & 0.42 & \multirow{2}{*}{ - } \\
\hline & & 0.10 & 0.65 & \\
\hline
\end{tabular}

Table 2. Results of secondary metabolite group identification of endophytic fungal of P. canescen leaf and C. tomentosa root

\begin{tabular}{ccccccc}
\hline Secondary & \multicolumn{9}{c}{ Fungal Isolate } & P.canscens & Fungal Isolate & C. tomentosa \\
\cline { 2 - 7 } Metabolite & DS21 & DS22 & DS23 & DS74 & AM61 & AM102 \\
\hline Alkaloid & + & + & + & + & + & + \\
Terpenoid-Steroid & + & + & + & - & - & + \\
Flavanoid & + & + & + & + & + & + \\
Polifenol & - & + & + & - & - & + \\
\hline
\end{tabular}

Description: $(+)=$ Secondary metabolites are identified

$(-)=$ No secondary metabolites are identified

From Table 1 and Figure 5. above, the amount detected of spot on chromatogram for each fungal isolate using
UV254 $\mathrm{nm}, \mathrm{UV} 366 \mathrm{~nm}$ and $10 \% \mathrm{H}_{2} \mathrm{SO}_{4}$ spotting is for isolate DS21 obtained by 4 spot on UV254 $\mathrm{nm}$ and UV 366 irradiation, 
and 8 spot on $10 \% \mathrm{H}_{2} \mathrm{SO}_{4}$ visible light. Isolate of DS22 obtained 3 spot on UV254 $\mathrm{nm}, 5$ spot stain on UV366 $\mathrm{nm}$ and 1 spot stain on $10 \% \mathrm{H}_{2} \mathrm{SO}_{4}$. Isolate of $\mathrm{DS} 23$ obtained each 3 spot on UV $254 \mathrm{~nm}$ and $366 \mathrm{~nm}$ UV and 1 spot stain on $\mathrm{H}_{2} \mathrm{SO}_{4} 10 \%$. As for the DS74 only obtained 3 spots on UV $366 \mathrm{~nm}$.

\section{Profile secondary metabolite}

Secondary metabolites of identification of four endofite fungal isolates from $\mathrm{P}$. canescen leaf and two fungal isolates from $\mathrm{C}$. tomentosa root using specific chemical reagents of spray compounds such as Dragendorf reagents for alkaloid, $\mathrm{FeCl}_{3}$ for polyphenol, Lieberman Bourchard for terpenoidssterols, and Sitroborat for flavonoid detection. The identification results showed that four isolates of $\mathrm{P}$. canescen leaf fungal contain alkaloid that is isolates DS (21, 22, 23 and 74), terpenoid - steroid isolates DS (21, 22, and 23), Flavanoid isolates DS (21, 22, 23 and 74), and polyphenol isolates DS (22 and 23). While the secondary metabolite identification endophytic fungal from $\mathrm{C}$. tomentosa rot results of two isolates contain alkaloid that is isolates AM (61 and 102), steroids isolate AM102, Flavanoid isolates AM (61 and 102), and polyphenol isolates AM102. The complete result of secondary metabolite group identification endophytic fungal of methanol extract two samples can be seen in Table 2 .

In Table 2, fungal isolates of methanol extract from P. canescens leaf showed that secondary metabolite contained in fungal isolates showed similarity of secondary metabolite contained in its host (P. canescens leaf) such as: alkaloids, terpenoids - steroids, flavanoid, and tannin (polyphenols) [9];[10]. Similarly, secondary metabolites of fungal isolates C. tomentosa root also show similar secondary metabolites with those present in their host plants: alkaloids, flavonoids, tannins (polyphenols), and phenolic [13].

\section{CONCLUSION}

1. Endophytic fungal that can be isolated from P. canescens Jack leaf amount to 4 types of fungal with isolate codes of DS21, DS22, DS23, and DS74, and two isolates of fungus from $\mathrm{C}$. tomentosa root with code isolates AM61 and AM102.

2. Profile of endophytic fungal isolates from P. canescens leaf are: greenishgreen colony, white gray-black base, rounded clustered shape, microscopically fungal having spores, sprangiosphora, sporangium, conidia, and hyphae. To isolate the fungal from C. tomentosa root are: clear black colonies, rounded fibers, there is blackish gray mycelium, flat colony, black pigment. Microscopic there are sprangiosphora, spores, conidia and stolon.

3. The secondary metabolites identified in the six isolates endophytic fungal of the P. canescens leaf are: alkaloids, terpenoids, and flavanoids, and polyphenols, and C. tomrntosa roots are: alkaloids, terpenoids, flavanoids and polyphenols.

\section{ACKNOWLEDGEMENTS}

Presented by the Dean of the Faculty of Pharmacy for the grant of the Scientific Research Group Research Faculty, Head of Research and Development Laboratory of Tropical Farmaka Faculty of Pharmacy Unmul for permission, facilities provided to support this research, as well as laboratory for the assistance and work of his saman.

\section{REFERENCES}

[1] Katno, Pramono S. 2008. Level Benefits and Safety of Traditional Medicinal Plants. Faculty of Pharmacy UGM; Jogjakarta. 
[2] Strobel, G.A. dan B. Daisy. 2003. Bioprospecting for Microbial Endophytes and Their Natural Products. Microbiology and Molecular Biology Reviews. Volume 67 Nomor 4: hal 491-502.

[3] Tan, RX and WX Zou. 2001. Endophytes: a rich source of functional metabolites. Nat Prod. Rep.18: 448-459.

[4] Tombe, M. 2008. Fungal Endofit As An Antibiotics Producer. C.V. Meori Agro; Jakarta

[5] Setyowati, M.F., 2010. Ethnofarmakologi and Usage of Medicinal Plants of Dayak Tunjung In East Kalimantan, Health $R$ \& $D$ Media, XX (3). Avalaible from: https://scholar.google.com.

[6] Al'amri, A.F., Herman., Amir, M. (2011). Antioxidant Activity of Merchant Root (Coptosapelta Tomentosa Valeton K. Heyne) Against DPPH Free Radicals (1,1 Diphenyl-2-Pikril Hydrazil). Bachelor's Thesis. Faculty of Pharmacy Mulawarman University.

[7] Kitagawa, I., Simajuntak, P., Hori, K., Nagami, N., Mahmud, T., Shibuya, H., Kobayashi, K., 1994. Indonesian Medicinal Plants. VII. Seven New Clerodane-Type Diterpenoids, Peronemins A2, A3, B1, B2, B3, C1, And D1, From The Leaves Of Peronema Canescens (Verbenaceae). Chem. Pharm. Bull. 42(5) : 10501055.

[8] Harmida, H., Sarno., Yuni., V.F., 2011. Ethnofitomedika Study In Lawang Agung Village Mulak Ulu Sub-District, Lahat Regency of South Sumatra. Journal of Science Research. 14 (1): 42-46.

[9] Ibrahim, A. and Kuncoro, H., 2012. Identification of Secondary Metabolites and Antibacterial Activity of Sungkai Leaf Extract (Peronema Canescens Jack.) Against Some
Pathogenic Bacteria. J. Trop.Pharm. Chem. 2 (1): 8-18

[10]Ramadenti, F., Sundaryono, A., Handayani, D., 2017. Ethyl Acetate Fraction Test Leaves Peresema Canescens Against Plasmodium Berghei At Mus Musculus. Alotrop Journal of Education and Chemistry. 1 (2): 89-92.

[11]Rosdiana, N.A., 2014. Active Antioxidant Faction Of Sungkai Wood Skin Extract (Peronema Canescens Jack.). Bogor Agricultural Institute.

[12] Ahmad, I., Ibrahim, A., 2015. Bioactivity Methanol Extract And NHexane Faction of Sungkai Leaf (P. Canescens Jack) Against Shrimp Larvae (A. Salina Leach). Journal of Science and Health. 1 (3): 114-119.

[13] Shella, A. 2011. Identification of Secondary Metabolites and BioEffectiveness Test of Rooted Roots (C. tomentosa Valton K. Heyne) Against Artemia Salina Leach. Bachelor's Thesis. Faculty of Pharmacy Mulawarman University. Samarinda.

[14] Kumala, Shirly, Erlita A., and Priyo Wahyudi. 2007. Activity of Secondary Metabolite Antimicrobial Capang Endophytic Trengguli Plant (Cassia Fistula L). Journal Alam Indonesia Vol. 6 No. 2: 46 - 48.

[15]Gandjar, I., W. Sjamsuridzal, and A. Oetari. 2006. Basic and Applied Psychology. Yayasan Obor Indonesia; Jakarta.

[16] Agusta, A. 2009. Biological and Chemical Fungal Endofit. ITB Publishers; Bandung.

[17]Djide, N. M. and Sartini. 2008. Analysis of Pharmaceutical Microbiology. Microbiology Laboratory of Department of Pharmacy UNHAS; Macassar.

[18] Jawetz, E., J. L. Melnick, and Adelberg. 2005. Microbiology For Health Professions. Translated by 
Huriati and Hartanto. EGC Publisher; Jakarta.

[19]Radji, M. 2005. The Role of Biotechnology and Endophytic Microbes in the Development of Herbal Medicines. Pharmaceutical Science Magazine. Volume 2 No. 3: pp. 113-126.
[20]Carlile, M.J., S.C. Watkinson, and G.W. Gooday. 2001. The fungal. Academic Press; California

[21]Rohman, A. 2007. Pharmaceutical Chemical Analysis. Student Library; Yogyakarta. 